\title{
Rendering Climate Comedy in Cloudy with a Chance of Meatballs 1 (2009) and 2 (2013)
}

\author{
Sabiha Ahmad Khan
}

Keywords: environment, food, animation, digital media, rendering, climate change

https://doi.org/10.1525/001c.13468

\begin{abstract}
This paper analyzes the Sony Pictures Animation franchise Cloudy with a Chance of Meatballs 1 and $2(2009,2013)$ in terms of its affective engagement with climate issues. Throughout the two films, the trope of constantly changing food weather is the subject of analysis and representation both diegetically by the films' characters and extradiegetically by the films' technical directors. Rendering the climate in an appealing way becomes paramount on the level of narrative and production. The treatment of food weather in the Cloudy films demonstrates the ways in which environmental animation mediates between, in the terms of C. P. Snow, the two cultures of the arts and the sciences. The Cloudy films, like many other examples of environmental animation, respond to Snow's call by deploying imaginative, often comic approaches to topics that in the mainstream media are treated logically and seriously, but with little impact on policy. In the case of the Cloudy films, that comic approach to environmentalism is tempered by the films' cooptation into a corporate responsibility campaign against food insecurity and by the fact that comedy is part and parcel of the business model of industrialized animation. Still, the technical challenges of animating and rendering food weather demanded that animators imaginatively experiment with actual food in a way that went over and above corporate policy. The arresting beauty and sensory engagement of the resulting animated food appeals to characters and viewers alike. Therefore, animated food-mediating nourishment and communication, science and art-may provide a productive inroad to exploring environmental issues.
\end{abstract}

Scripted as a parody of cli-fi films (Lee 2006), Cloudy with a Chance of Meatballs 1 (2009) and 2 (2013) propose an animated comic alternative to tragic environmental end-of-world accounts. The first film is an adaptation of Judi Barrett's 1978 eponymous children's book, which recounts life in an Edenic place called Chewandswallow where the weather is edible. All of a sudden, the weather changes, and the citizens of Chewandswallow are forced to evacuate and work for their bread. The first Cloudy film differs significantly from the book in that it is not a story of an Edenic fall from grace but a story of technology run amok. Renamed Swallow Falls, the island setting for this Sony Pictures Animation franchise is a sardine fishing-based economy shattered by cataclysmic food weather composed of bulleting burgers and cyclonic spaghetti. As the first Cloudy film details, these atmospheric disturbances were seeded by a food-making machine, the Flint Lockwood Diatomic Super Mutating Dynamic Food Replicator, or FLDSMDFR for short, which was invented by and named for the film's protagonist. Cloudy's sequel, pitched as the "leftovers" of the first act, features food-animal hybrids called foodimals that form the basis of a monster film parody (Miller-Zarneke 2013, 86). As fictional animated features designed to entertain kids and adults, the Cloudy films use neither the serious evidence-based work of climate science nor the moralizing jeremiads of the environmentalist movement (Opie and Elliot 1996). Rather, the two Cloudy films provide an unexpected entry point to climate change topics through the dual approaches of comedy and playfulness, 
which many have argued allow for affective engagement as well as ironic selfreflection on climate change (Boykoff, McNatt, and Goodman 2015; Brereton 2014, 2015; Heise 2014; N. Seymour 2018; Starosielski 2011; Todd 2015).

The Cloudy franchise therefore takes its place among what Nicole Starosielski has characterized as a long line of environmental animated films since World War II that visualize the environment in one of three ways: "as mutable, as interactive and as constructed" (Starosielski 2011, 148). The Cloudy films exhibit some aspects of all three waves of environmental animation through their elaboration of the causes and effects of food weather on Swallow Falls. The environment of Cloudy 1 is mutable in the sense that the FLDSMDFR depends on the precipitation of clouds to make the food weather. This understanding of clouds, according to Esther Leslie, is in keeping with their status from the industrial to the digital age as animating phenomena that are "preoccupied with making forms" (Leslie and McKim 2017, 236). That the citizens of Swallow Falls can make requests to Flint for specific food weather suggests that the environment in Cloudy 1 is interactive on account of the citizens' agency in changing their milieu according to their appetites. That the same milieu morphs in Cloudy 2 into a self-sufficient ecosystem of foodimals, in turn, grants agency to that newly evolved food-based species. Finally, the constructed nature of the Cloudy universe comes to the fore with the prevalence of screens and cameras throughout the narrative to allow the characters in that universe to witness and question official narratives about the food weather as it unfolds.

As Starosielski $(2011,159)$ argues, all these aspects of environmental animation could prove to be "valuable in our current political climate," where the operationalized discourse of climate change mitigation and downright denial dominates policy discussions. More crucially, the shifting back-and-forth that Starosielski observes in environmental animation accurately captures the metabolic flow between humans and the environment as well as the semiotic dimensions of ecosystems that Bronislaw Szerszynski argues have been largely ignored by the rationalistic logic of "climate technics" (Szerszynski 2010, 13). I therefore approach the Cloudy films not as pure fiction but as "subjunctive documentar[ies]" (Wolf 1999, 274) that engage food as a medium for "environmental imagining" (Carruth and Marzec 2014, 206) in a comic tone. That imagining occurs through the diegetic conceit of food weather and the extradiegetic technical tinkering necessary for animators to render that food weather into existence on the screen.

\section{Climate Comedy}

In the Cloudy films, we witness the comic potential of the film in Flint Lockwood's playful approach to technological innovation. That approach intertwines Flint's self-knowledge with that of his surroundings, an emergent ethical model in ecopoetic children's narratives, according to John Stephens (2010, 209-10). The opening sequence of the first film features Flint as a 
geeky youth, devising ways to make his prepubescent life easier, albeit endlessly ridiculed, with novelties such as Spray-On Shoes that never come off and the Party in a Box that, with the press of a button, instantly delivers a festive atmosphere, complete with ill-timed explosive confetti. Not simply his inventions but his entire scientific infrastructure comprises a game of childhood make-believe extended into early adulthood: he still wears a nowoutgrown lab coat that his mom had given him before she died; his equivalent of a Batcave teeters precariously on the foundation of his former tree house; the walls of his lair are little more than Tron-themed wrapping paper; and his lab assistant is a monkey equipped with a "Speak and Spell" universal translator whose well-timed utterances serve as both punny punch lines and the possible beginnings of interspecies communication.

Unlike his previous inventions, the FLDSMDFR is a big hit among the inhabitants of Swallow Falls, which in turn prompts the mayor to change the island's name to Chewandswallow (in line with the source text of the film) and shift the entire economy of the island from its monocultural sardine fishing base to global food tourism (Barrett 1978). An absurd ecosystem of businesses pops up, such as the exclusive Roofless Restaurant, where food from the sky plops directly onto your plate, a bib store, and a company selling Flint Lockwood-themed napkins. A device called the Outtasighter shovels the inevitable surfeit into new geological formations such as Mount Leftovers and the Nacho Cheese Hot Springs. A concretization of human-generated climate change writ large, the food weather's afterlife is both testament to human excess and a fun thought experiment about what would happen if humans no longer relied on agriculture for their food.

Environmental animation, in its imaginative speculation on the contours of future worlds, performs an important interpretive function at this crucial moment in public discourse on climate change. Policy discussions persistently call for incremental climate change mitigation in the face of an impending extinction event, what Tom Cohen has called a logic of "managed extinction" (Cohen, Colebrook, and Miller 2014, 20). Animated elements such as food weather potentially help dislodge such discussions by calling into question the notion of gradual climate change; the outsized food weather, for instance, seems to emerge in a matter of days after Flint's machine is overly taxed by the citizens' food requests. Once the FLDSMDFR reaches its breaking point, the Romantic-era maxim "you are what you eat" (Morton 2016, 128) comes to bear not only on the people of Chewandswallow but on the island itself, which transforms into an ecosystem for the foodimals. Cobbled together from plants, animals, and industrial food, the foodimals are more than the sums of their parts. From the "Tacodile Supreme" to "Fruit Cockatiels" to "Su-sheep" to the single-ingredient foodimals such as "Cantelopes," the foodimals are food come to life through a combination of human artistry and vegetative growth, though it is difficult to see where one begins and the other ends. As living 


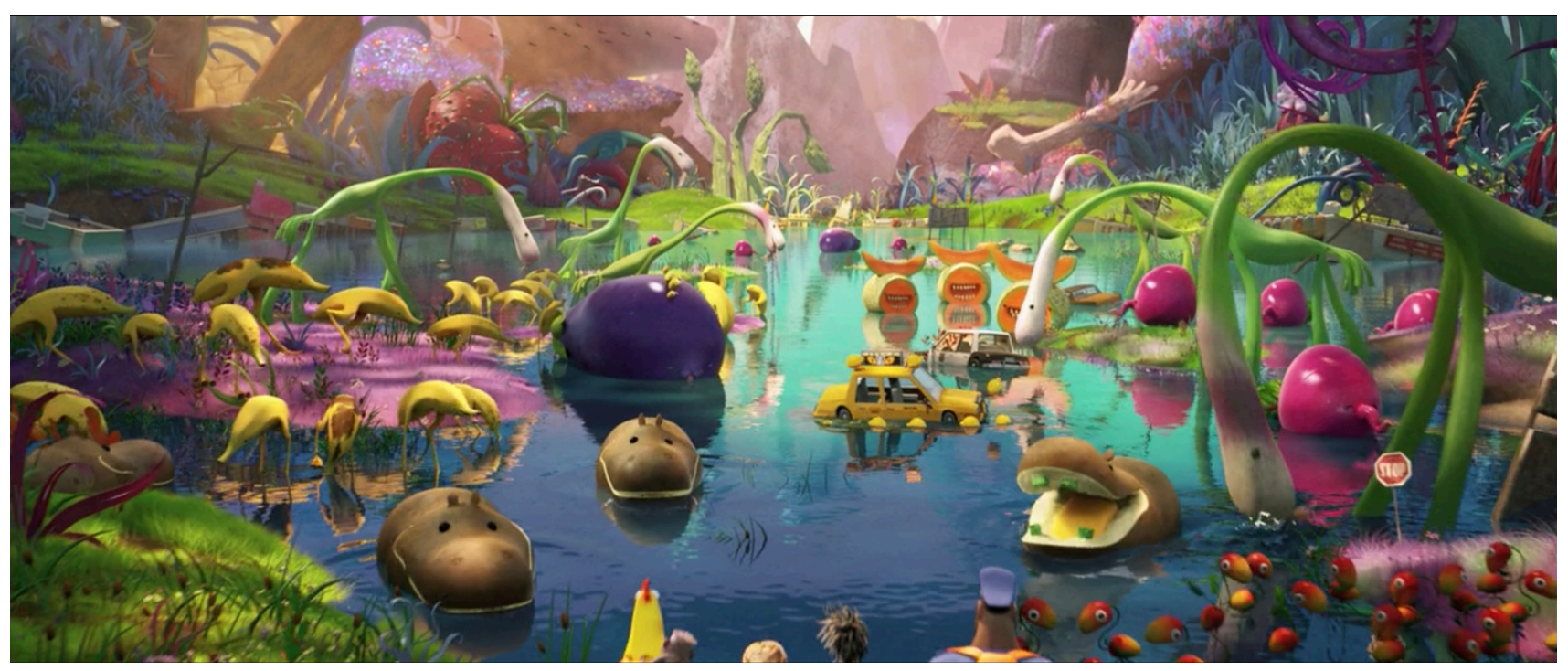

Figure 1: The foodimals and their ecosystem (Cloudy 2).

portmanteaux of the worst of North American and global culinary excesses, the foodimals represent an absurd world where the categories of the living and the dead, the natural and the artificial, science and art, are up for grabs (figure 1).

The status of foodimals as imaginative figures for thinking through environmental science speaks to a concern voiced by C. P. Snow sixty years ago in his Rede Lecture at Cambridge University entitled "The Two Cultures and the Scientific Revolution." Snow's address challenged British intellectuals at the time to consider the societal effects of enduring disciplinary silos between the humanities and the sciences. Snow (1993, 27) cites the Agricultural and Industrial Revolutions as the most dramatic shifts up until that point in history in raising human standards of living but argues that humanists at the time looked the other way, never bothering to understand "the base of our social hope." Now, as the Digital Revolution transitions into narrowing the distance between representation and experience with the advent of virtual and augmented reality, humanists are in a situation similar to their forebears. This newest iteration of the Digital Revolution, combined with the global environmental impacts of the previous two major technological revolutions, is bringing the geological period of anthropogenic climate change, known commonly as the Anthropocene (Crutzen and Stoermer 2000), to a head. In the same stroke, the Digital Revolution's proliferation of the image ironically has blinded people to the reality of climate change.

In this vein, the food weather in Cloudy 1, as the product of the human appetite for consumption, acts as a vivid, comical parody of the Anthropocene. For Tom Cohen, this type of "climate comedy" is perhaps the most realistic approach to representing climate change at the current point of no return (Cohen, Colebrook, and Miller 2014, 26). Greg Garrard (2011, 93) advocates "comic apocalypticism" as a way of focusing on contingency and openness, 
which may in turn allow for radical action. Allison Carruth $(2018,111)$, in turn, finds that comic or "wily" ecological texts often "disrupt or retool wellknown environmental genres" that fall within more traditionally tragic modes. David Whitley's (2012, 152-55) reading of Wall-E, for instance, argues that the pastoralism of Disney's Bambi is subversively redefined in Wall-E through the detritus of the humorously quaint consumer kitsch that populates Wall-E's post-apocalyptic world. Similarly, in the Cloudy films, the mechanism whereby the foodimals' lush ecosystem emerges is ironically the very consumerism that fuels people's desires.

Flint, in his repeated attempts to improve life for others, pushes technology too far by trying to bypass agriculture with the FLDSMDFR. In the process, he creates more problems: food weather that threatens to swallow the earth through its size and mutated living food that will do everything in its power to survive. Initially described as "manna from heaven" by Lockwood's weather reporter love interest, Sam Sparks, the food weather quickly escalates into a "perfect food storm" that threatens to turn the Northern Hemisphere into "one big potluck" (Cloudy 1). This analeptic jump from Exodus-the occasion for a utopic gathering of manna that obviates agriculture-to the Deluge-which marks the beginnings of the agricultural era-points to the endless feedback loop in which we find ourselves, climactically speaking. Timothy Morton has described this as the "Oedipal logic of ecological awareness," a "self-destructive tendency within agriculture itself . . . which all the time appears as . . . the conquest of space, the subjugation of nonhuman species" $(2012,16)$ and the "agrilogistic[al] prioritizing of needs over wants" (2016, 43). This is why, as Tom Cohen notes, even imaginative experiments in postapocalyptic film propose endings of "managed extinction" (Cohen, Colebrook, and Miller 2014, 20), when humans reach the brink of extinction, only to redeem themselves at the last minute. Even C. P. Snow (1993, 102n15) seems to intuit the hollowness of agrilogistical logic when he surmises in a footnote in The Two Cultures that the transition to agriculture from a hunting and gathering society "must have been a genuine spiritual impoverishment [for some]."

Despite their playfulness, therefore, the Cloudy films persist in being read in agrilogistical terms. This tension between need and want surfaces in a number of different ways, including the films' reception, the understanding of the FLDSMDFR within the plots of the films, and, transmedially, as part of the films' participation in a wider campaign against food insecurity. An NPR reviewer of the film casts it as a movie that acts as "a PSA for portion control" that "brings to candy-colored life the junk food fantasies of every child and former child in the audience" (Taylor 2009). The reviewer continues, "Unhealthful nutrition may be bad for you, but oh, what fun it is, at least until you start getting sick." Careful to assess the film's fun factor without "slipping into preachy sanctimony," the reviewer tries to strike a balance in her reading of the film (Taylor 2009). Her reaction is similar to that of the production 
team on the Cloudy 2 film, who at first attempted to divide the foodimals into "good" and "bad" food. Kris Pearn, the film's co-story director, explains that "it became difficult to determine if healthy/organic food was meant to be good and junk/processed food should act badly, or vice versa ... so after countless conversations ... we simply asked, 'What's funny?'” (Miller-Zarneke 2013, 86). Here, comedy serves to counteract the agrilogistic division between good food and bad food, needs and wants.

An agrilogistician's dream come true, the FLDSMDFR is the ultimate in ensuring social control through food security, which is not lost on the figures of power in the two films, the mayor of Swallow Falls in Cloudy 1 and tech guru and entrepreneur Chester V in Cloudy 2. While food security would seem to contribute to the sustainability of social movements (Mirzoeff 2014), Cloudy 1 and 2 show us the sinister side of cornucopic plenty. In Cloudy 1, the mayor of Swallow Falls immediately pounces on the FLDSMDFR as the key to rebooting the island's economy from its former monocultural base in sardine fishing to tourism. The citizens of Swallow Falls do not notice the mayor's unilateral implementation of this new economic policy because they are too busy devouring the food weather that Flint continues to whip up for them on request. In Cloudy 2, Chester V, Flint's childhood scientific hero and a parody of Steve Jobs, sees the FLDSMDFR as the missing link to upgrading the latest iteration of his human "operating system," the Food Bar 8.0. With it, Chester V believes he will be able to bypass the pesky business of agriculture and directly tap into the vegetative potential that food growers of all stripes hope for in precipitation.

Sony Animation formalized the agrilogistical implications of the FLDSMDFR in the form of a transmedial partnership with Feeding America and Burger King. Sony Pictures executive vice president of global consumer marketing at the time George Leon commented, "Cloudy with a Chance of Meatballs 2 is a fun adventure film, but ultimately, it's about an inventor trying to make the world a better place through food" (Feeding America 2013). Another PSA called "Hunger Helpers" starts with a scene of Flint instructing the FLDSMDFR to "Get food to people who need it." The voiceover in the PSA intercuts between scenes of Flint discovering the food-making potential of the FLDSMDFR, stating, "You may not be able to make food fall out of the sky . . . But you can fight hunger in your community" (Feeding America 2009b). The Burger King campaign, in turn, co-opted the film's ethos of play as part of its corporate responsibility mission by creating product tie-ins such as Meatballs-themed kid's meal toys and a website featuring a "Food Catcher" game where kids use points they accumulate through playing the game to give virtual donations to Feeding America that would be matched by corporate sponsors (Feeding America 2009a, 18). By emphasizing the ways in which people are food insecure, the Meatballs transmedia campaigns draw upon the sense of insecurity embedded within agrilogistics and blunt the playfulness of Flint's invention by using it to fulfill needs rather than wants. 
What the transmedia campaigns get wrong, above all, in their treatment of food weather as a solution for the social problem of food insecurity is their understanding of weather as something that can be read and responded to in literal terms. The same technical, "logocentric" reading of the weather, according to Bronislaw Szerszynski (2010, 23), guides how policies of climate mitigation proceed. The food weather in the Cloudy films is much more fluid, particularly in its transformation first into sentient food and then into the foodimal ecosystem. In its various forms, the food weather actively accounts for shifting metabolic interactions between humans and the environment such that it both recapitulates Starosielski's typology of environmental animation and breeds what Szerszynski $(2010,25)$ describes as "new relations of interdependence." Similar to the way in which nutritional epigenetics posits that experimentally administered food constitutes the environment of the subject in question (Landecker 2011, 168), the food weather in Chewandswallow becomes both threat to and the very substance of the humans who reside there. Children get sick off the junk food weather, and the mayor's bodily proportions expand in concert with the food weather's increasing size.

The food weather, however, also has a positive effect when it transforms the town bully and former child spokesperson of Swallow Falls' sardine industry, Baby Brent, into the human-poultry hybrid Chicken Brent. In his new, multispecies form, Chicken Brent feels he can "finally contribute to society." His shift from entitled brat to responsible citizen affirmatively answers Stacey Alaimo's $(2016,1)$ recent question about the radical possibilities of "multispecies liveliness": "Can exposing human flesh while making space for multispecies liveliness disperse and displace human exceptionalism?" The films' treatment of exposure to the environment, though perhaps risky for humans, could be the basis for the playful and unpredictable-hence comic-refocusing of life beyond the human. The Cloudy films' commitment to a comic environmental mode, therefore, rather than fruitlessly lament an extinction event to come, describes imagined environments in terms of their contingent, indeterminate, mutable status, which could leave space to contemplate radical action in the real world.

\section{Visualizing Climate Comedy}

The urgency of climate change often is lost on account of its perceived temporal remoteness and its massive spatially distributed scale, which makes visualizing it for lay audiences all the more challenging (Mirzoeff 2014; Morton 2013). Environmental animation, however, has always shown "potential for visualizing imperceptible environments” (Starosielski 2011, 159). At stake in the study of environmental animation and other subgenres of ecocinema, therefore, is what Sean Cubitt $(2012,294)$ describes as a reckoning with the "visualization ... technologies used to mediate between three sets of agents: the scientific community, the natural world, and the mass of the population." In Cloudy 1, Weather News Network reporter Sam Sparks globally tracks the food 


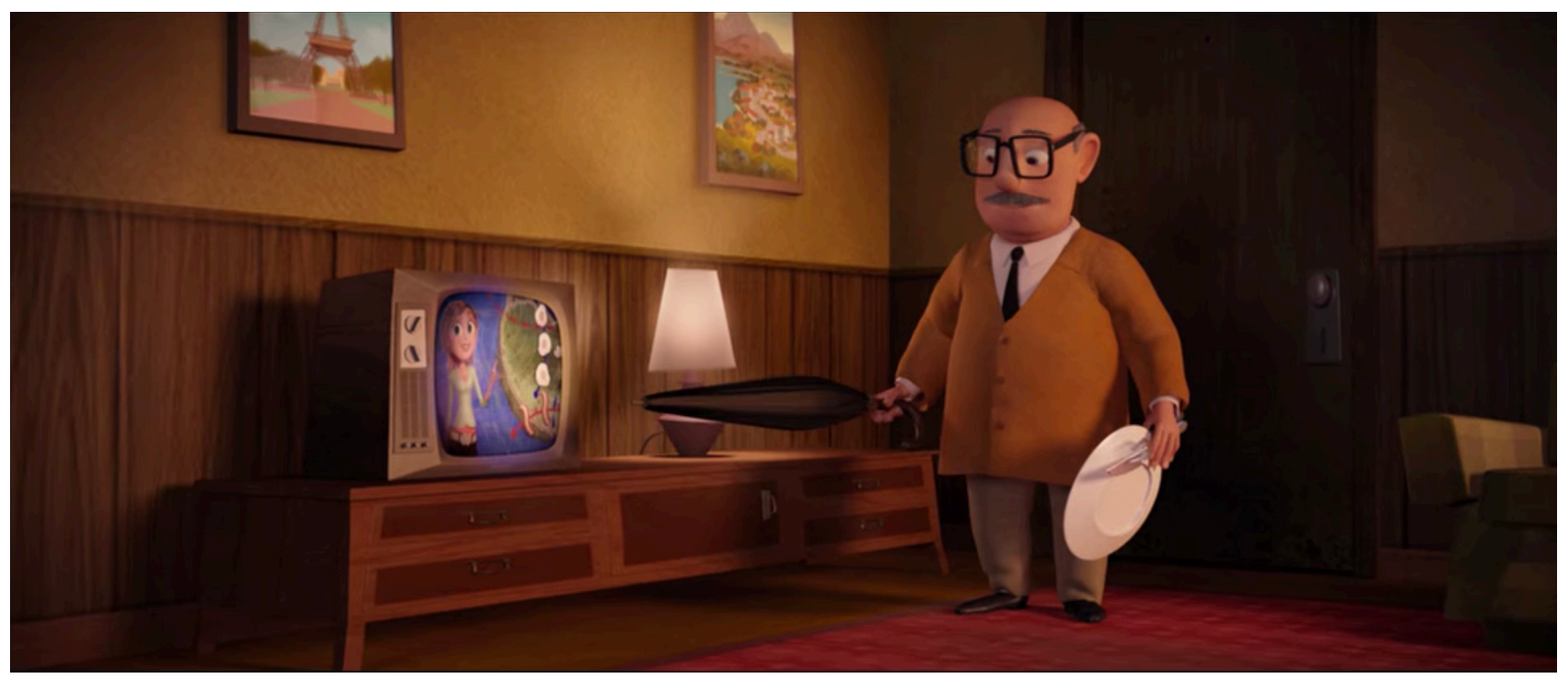

Figure 2: A Swallow Falls resident considers his options upon watching Sam Sparks's food weather report (Cloudy 1).

weather on her Weather Radar 2000 Turbo. Her analyses are rendered into video feeds shot by her camera operator, Manny. These feeds are then broadcast to the film's diegetic viewers on everything from TV screens to cell phones to a walking, semisentient monitor that Flint has named the Remote-Controlled TV (figure 2).

The diegetic viewers may perceive these screens, as many real-life viewers do, as "windows" to the natural world (Cubitt 2012, 293). However, the extradiegetic viewer, aided by Sam Sparks's overt challenge to her editorial overlords, witnesses the ways in which corporate outlets such as the fictitious Weather News Network try to capitalize on the inherent drama of inclement weather. Sparks's report on the food weather embodies in large part what Julia Leyda and Diane Negra $(2015,3)$ call the "mixed affective register" of disaster media, which, much like agrilogistical discourse, capitalizes on feelings of insecurity. Humor, however, is also part of that affective mix.

The first Cloudy film in fact had a humorous promotional tie-in with the Weather Channel, with one of its on-camera forecasters presenting a punfilled report mimicking that of Sam Sparks (Nudd 2009). Sam Sparks's punny reporting of the weather is an example of climate comedy that through its repetition and vivid description in language dilates temporally the experience of the weather. In the midst of a burger rain, Sam Sparks addresses the camera, saying, "You may have seen a meteor shower, but you've never seen a shower meatier than this." When fried eggs descend on a cloudless day, she says the weather is "sunny side up." Chicken raining down is "poultry in motion." And ice cream flurries transform Chewandswallow into a "town that is truly à la mode." Focusing on the spectacular effects of outsized food weather, Sparks elevates the otherwise mundane topic of the weather-what Leyda and Negra $(2015,1)$ call the ultimate "phatic discourse"-into the stuff of cinematic 
wonder and delight. Moreover, her "aesthetic amplification" of the weather through creative description shifts the temporal possibilities of the disaster by registering "fluctuating details of change... in order to open out towards a less teleological sense of the future" (Smailbegović 2015, 98).

Critics such as Rey Chow (2011, 143), however, have questioned the utopic potential of such moments of reflexivity within a media environment where "proliferating hypermediatized screens and frames" are the norm. The characters' scrutiny of the foodimals, however, marks their attempt to read and learn from the environment in new ways. Sam Sparks, for instance, realizes that the aggressive behavior of an ambulatory man-eating taco, dubbed the Tacodile Supreme by Manny the camera operator, was not unmotivated; the Tacodile Supreme was in fact a mother protecting her defenseless Tacodile cubs from the Sentinels of Safety (figure 3). In this process of repeated looking, the protagonists slow down the rapid throughput animating force of the FLDSMDFR and metatheatrically undercut the heroics of digital animation that are the films' conditions of possibility.

In another scene, a rabid pack of carnivorous, ambulatory pickles threatens to attack Tim Lockhart, bait shop owner and Flint's father. As Tim contemplates the absurdity of being devoured by a family of brined cucumbers, he is confronted with the rapacity of his own species; as the owner of a bait shop and enabler of such rapacity, the irony of his impending status as future food cannot be overstated. Eventually serving as a fishing mentor and father figure to this gherkin clan, Tim seems to approach a cross-species kinship. This moment in the Cloudy diptych is significant in its representation of what J. T. Barnett (Barnett 2018, 228) has called the "politics of edibility": that for humans to think of themselves as food for other organisms allows them to "acknowledg[e] ... the interconnectedness and interdependency of all beings" (figure 4). Swallow Falls therefore gives birth to not only a new type of weather that demands a new way of looking and understanding, but a new species that mirrors back to humans in a feedback loop their own rapacity.

\section{Rendering Climate Comedy}

The Cloudy films' depiction of proliferating screens as the means whereby characters witness the global climate catastrophe of food weather is symptomatic of the early twenty-first century release of the films, a crucial transition in the ongoing Digital Revolution. During this transition period up until the present, the digital media and visual effects industry has seemed to be caught up in minimizing the delay between figuration and experience through augmented and virtual reality technologies. The 2018 keynote at the Association for Computing Machinery's computer graphics SIGGRAPH conference stressed this fact. The 2018 SIGGRAPH keynote speaker, Rob Bredow, currently the executive creative director and head of Industrial Light and Magic, focused his address on the importance of "real-time techniques," which he described as a "win all-around" (SIGGRAPH Conferences 2018). 


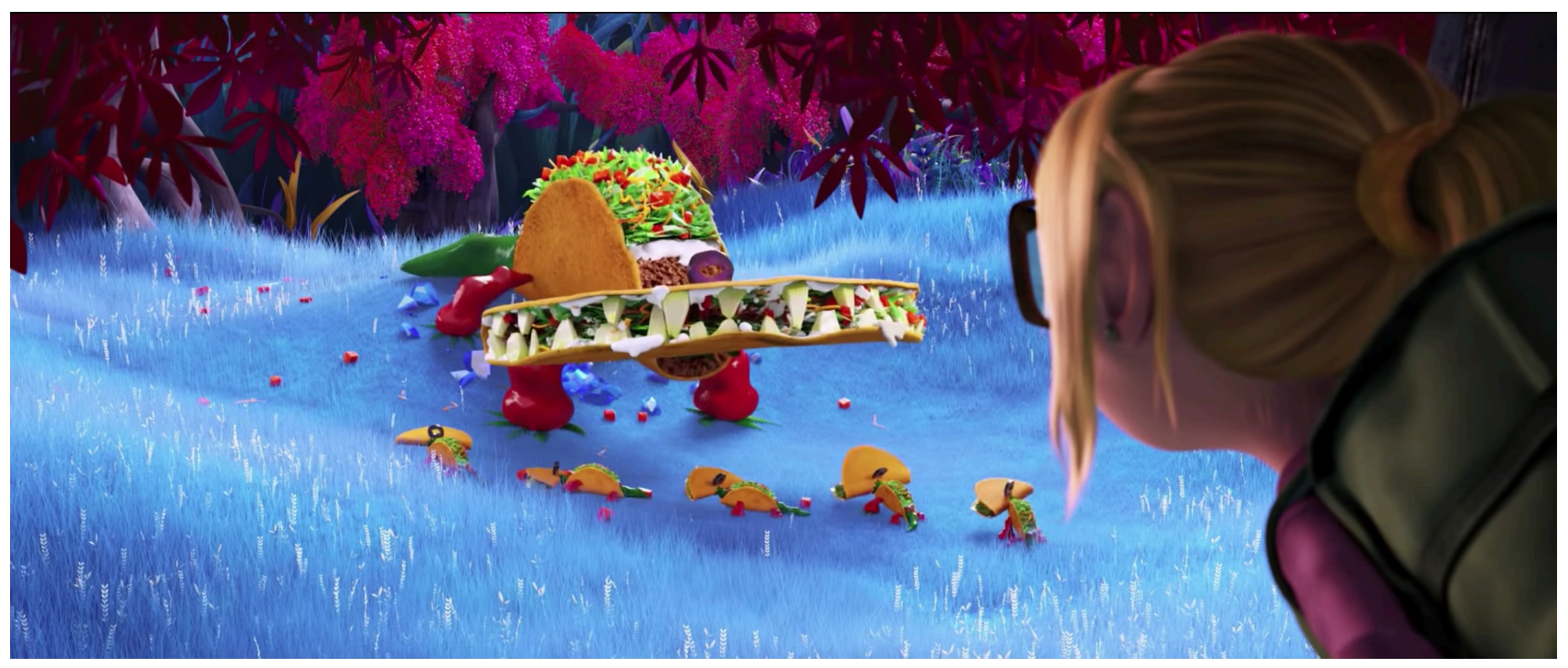

Figure 3: Sam Sparks observes the Tacodile Supreme shepherding her cubs to safety (Clondy 2).

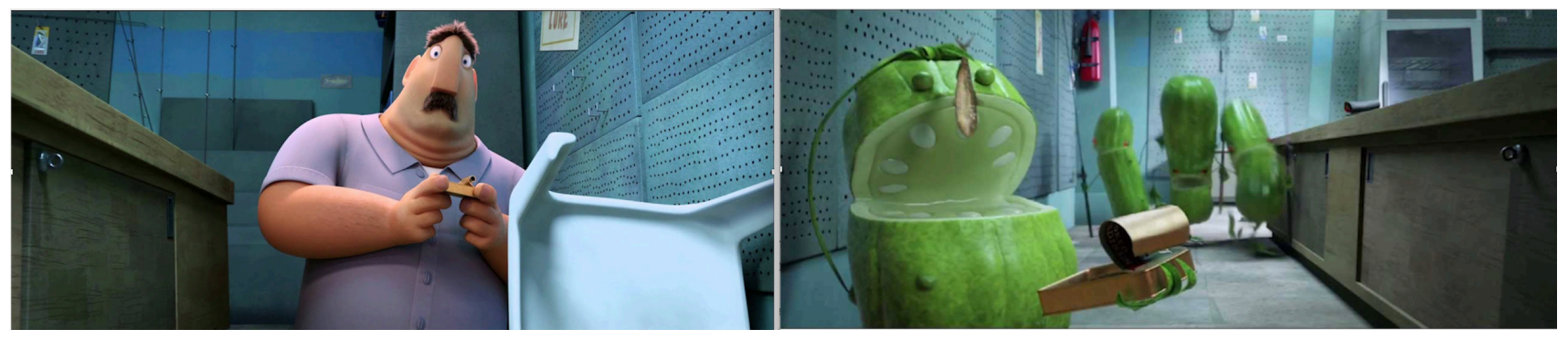

Figure 4: Tim Lockhart contemplates his edibility upon encountering a carnivorous pack of pickles (Cloudy 2).

This move toward real time was in effect even during the production of both Cloudy films, since, in fact, Bredow oversaw their production as chief technical officer and visual effects supervisor at Sony Pictures Imageworks (SPI).

The benefit of "real-time rendering techniques" in the context of virtual and augmented reality is that they allow viewers to change their points of view and see something instantaneously, without delay, as if it actually were before them. Artistically, as Bredow states, real-time rendering is huge: for actors and camera operators, green screen and motion capture filming is grounded visually within the world of the story rather than being an abstractly choreographed exercise (SIGGRAPH Conferences 2018); for digital effects, computer graphics, and animation folks, real-time rendering allows them to play around with the digitized environments they create and test out possible scenarios (M. Seymour 2012, 13). The economic implications of real-time rendering are enormous, since "rendering is always an exercise in managing how much computer power you are willing to devote to simulating reality" (M. Seymour 2012, 1). With budgetary constraints out of the way, real-time rendering asymptotically promises the ever-receding horizon of perfectly embodied imaginary worlds. 
Critical climate change theorist Claire Colebrook $(2014,21)$ has argued that these increasingly unmediated visual "replicating technologies" have something fundamentally in common with "life-propelling investments" associated with settled agriculture: both are essential to survival and have inured human beings against seeing their impact on the climate. But the particular pressures of the Cloudy animators to make the food weather look good enough to eat (Robertson 2009, 17) ironically disrupted the corporate mission to aim for a near-real time, immersive experience. On the one hand, there is a sense of indexical realism to the food in the Cloudy films that trickles down to the technical details of animation: actual food was used to model its physical behavior and to create sound effects ("Film Sound" 2013, 2). Yet these very efforts by the animators also underscore the ways in which food is both a communicative and a nourishing medium (Barthes 2013; Mitchell 2010, 14). Without having interacted with the physical food, the animators would not have been able to figure out how to visualize it accurately. The realism of the food in the films in turn depends on the relative lack of realism in the human characters, whose exaggerated, comic, stylized movements are akin to the 2D animation associated with United Productions of America (Boulos 2016, 8; Robertson 2009, 15).

Animating the food weather and the foodimals proved to be challenging to the animators, but the difficulties were assuaged in part by the advent of near-real time rendering techniques that allowed for animators to constantly tinker with the way in which food acted in modeled environments. During the production of Cloudy 1 at SPI, Rob Bredow led the implementation of Arnold, a raytracing renderer designed for the production of visual effects and animation. Arnold allowed for the efficient rendering of detailed environments, textures, and lighting. The result was that various stages of animation could be worked out through trial and error without using up excessive processing power and time (M. Seymour 2012, 13). Ray tracing simulates the effects of physical light on objects in a computer graphic environment by drawing lines between a central light source-a feature called global illumination - and modeled objects (M. Seymour 2012, 37). The Arnold ray tracer was one of the fastest ray-tracing renderers in the industry, fast enough to give results in near-real time. Initially designed by programmer Marcos Fajardo and later adopted as SPI's in-house renderer, Arnold's nimbleness has been attributable to Fajardo's team's constant optimization of the "speed of the rays and the number of the rays" illuminating a particular surface (M. Seymour 2012, 33). By using the average of a large number of random samples-what's called a Monte Carlo integration-Fajardo's team has been able to produce a variety of realistic visual, physics-based effects such as motion blur, depth of field, and soft shadows without having to excessively tweak the results through graphical manipulation (Kulla et al. 2018, 9; Martinez and Tornberg 2010, 1; M. Seymour 2012, 35). Compressing data further enhanced the efficiency of the system (M. Seymour 2012, 30, 13). 
Capitalizing on the efficiency of the Arnold rendering system through its proprietary version of it, SPI maximized the amount of detail available to play with for artists working on both Cloudy 1 and 2. The first film boasted fifty different types of food and a very large set of the town of Swallow Falls, which was redone five times ("A Recipe" 2010). All these different foods meant that the animators were working with a wide variety of surface textures. Such variety in texture would in other circumstances have made lighting a time-consuming affair. Ray tracing made the lighting process much more efficient because it took into account each surface texture's physical response to light. That meant that lighting setups did not have to be changed between shots but could be set at the beginnings of sequences, thereby allowing artists to tinker more with the blocking of shots within sequences without having to worry about relighting (Martinez and Tornberg 2010, 1). On Cloudy 2, a tool allowing for "depthbased compositing" enabled several artists to work on the same shot at the same time and see the results of their changes in near-real time (Govil 2017, 1). By being able to include large amounts of lush, textural detail in terms of both environments and characters, the animators were able to test the limits of the interactions of large food weather with the built environment (M. Seymour 2012, 26; Robertson 2009, 19). In doing so, they were able to test the limits of materiality itself.

The food collisions in particular provided a key instance for testing the capacity of the Arnold system to render the hypothetical scenarios quickly enough that artists could iteratively approach a desired look. The complexity of the foods involved and intensity of their collisions with architectural and geographical features on the set made designing the collisions particularly difficult, as Rob Bredow explains: "We drop food that's made of more than one piece, and that interacts with whatever it hits ... A pancake hits a school. A jalapeño pepper explodes into a giant fireball. The interactions are extreme" (Robertson 2009, 19). Because of the scope of the collisions, each hit was not hand animated; rather, the food and buildings were modeled with various levels of detail and then processed through an open dynamics engine that generated the physics of the interaction. The buildings were modeled with intricate details from facade to plumbing and then were set to explode in various directions once they were hit with the food weather ("A Recipe" 2010). The food weather required a two-step process where a low-resolution geometric chain of scaffolding approximating the shape of the food weather was linked to a high-resolution image of it. This process allowed artists to predict and adjust the movements of the food weather without having to render the images down to the last detail (Robertson 2009, 19). While this technique of rigging and running a modeled object through an open dynamics engine is standard practice in computer animation, there is a way in which the food weather, when subject to this treatment, emerges as a comical abstraction of itself (Robertson 2009, 19). As described by a number of artists working on the first Cloudy film, behemoth bananas in their pre-rendered, low-resolution state are covered in a polygonal armor that articulates their trajectory through the sky. Stormy spaghetti is 


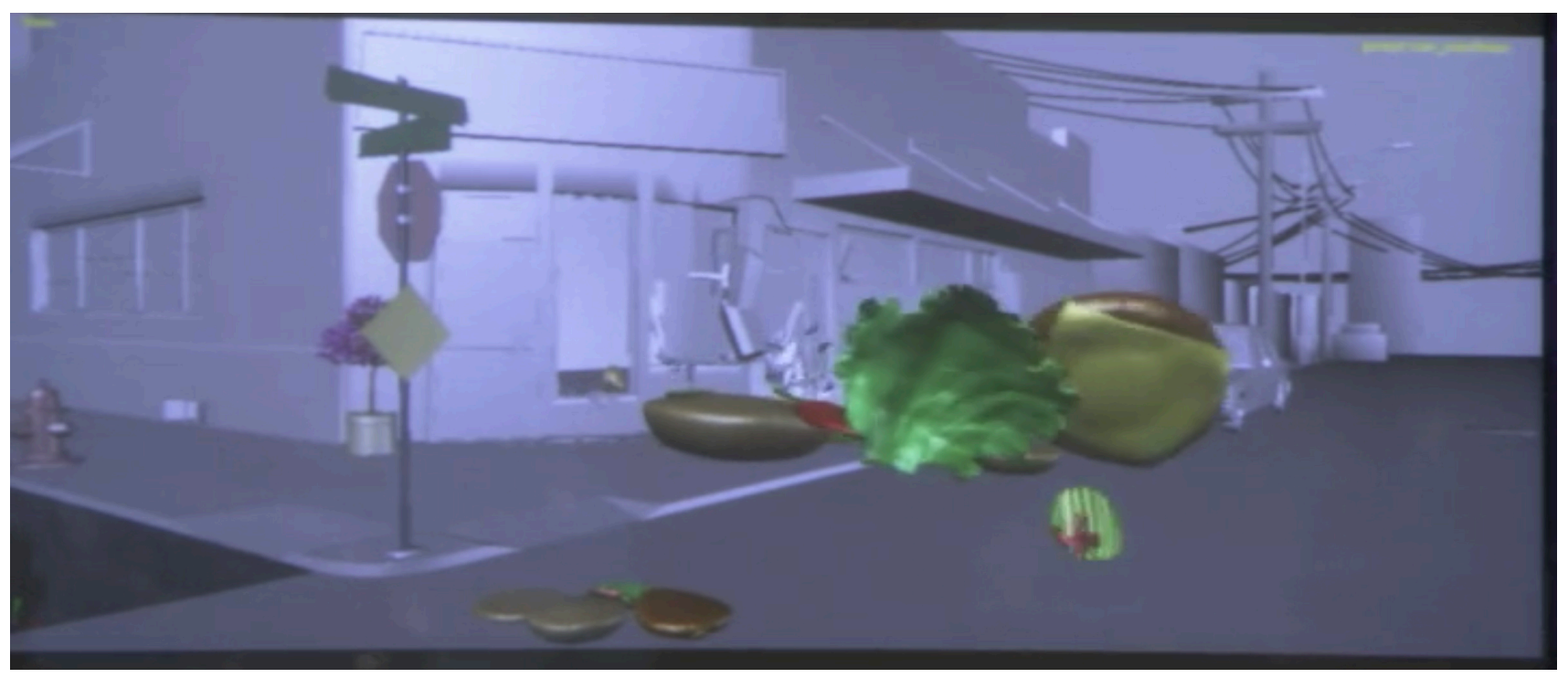

Figure 5: Animators test the trajectory of a falling burger (A Recipe for Success).

generalized to curves comprising a new "noodle geometry." And the various layers of a burger-down to the last sesame seed-are rigged as innumerable connected "semi-rigid convex bodies" that beat down from the heavens onto the pavement, sending buns, patties, and tomatoes rolling and condiments splattering, all according to the laws of physics (2009, 20; "A Recipe" 2010) (figure 5).

Yet not everything is automated; as one animator on the first Cloudy film explains, "Every time the meatball plows through a house, somebody has to go through and break that house up, and make it explode at the right time" " $\mathrm{A}$ Recipe” 2010). That tension between the self-propelling motion of physically based modeling and the tweaking allowed by a keyframing approach preoccupied researchers in computer graphics in the late 1980s as well, when many of the advances in physically based modeling were taking place. At a 1989 ACM SIGGRAPH panel on "Physically-Based Modeling: Past, Present, Future," the discussion focused on the tension between the limits of physicsand human-based modeling. James Blinn, a pioneer in rendering from Caltech who also did animations for NASA's Voyager mission and Carl Sagan's Cosmos series, described the challenge of physically based modeling as follows: "You give the simulation some initial conditions and stand back and let it fly and see what happens. The big trick is controlling it to do what you want" ("PhysicallyBased Modeling” 1989, 13).

A big challenge in the late 1980s was realistically rendering "deformable models" whose various parameters-including shape, texture, and shading-were constantly in flux. Food was often used as fodder for such early experiments because of its textural variety and irregular forms, with one food-based material in particular capturing the imagination of the computer graphics community: Jell-O ${ }^{\mathrm{TM}}$ brand gelatin dessert. An ongoing "community 


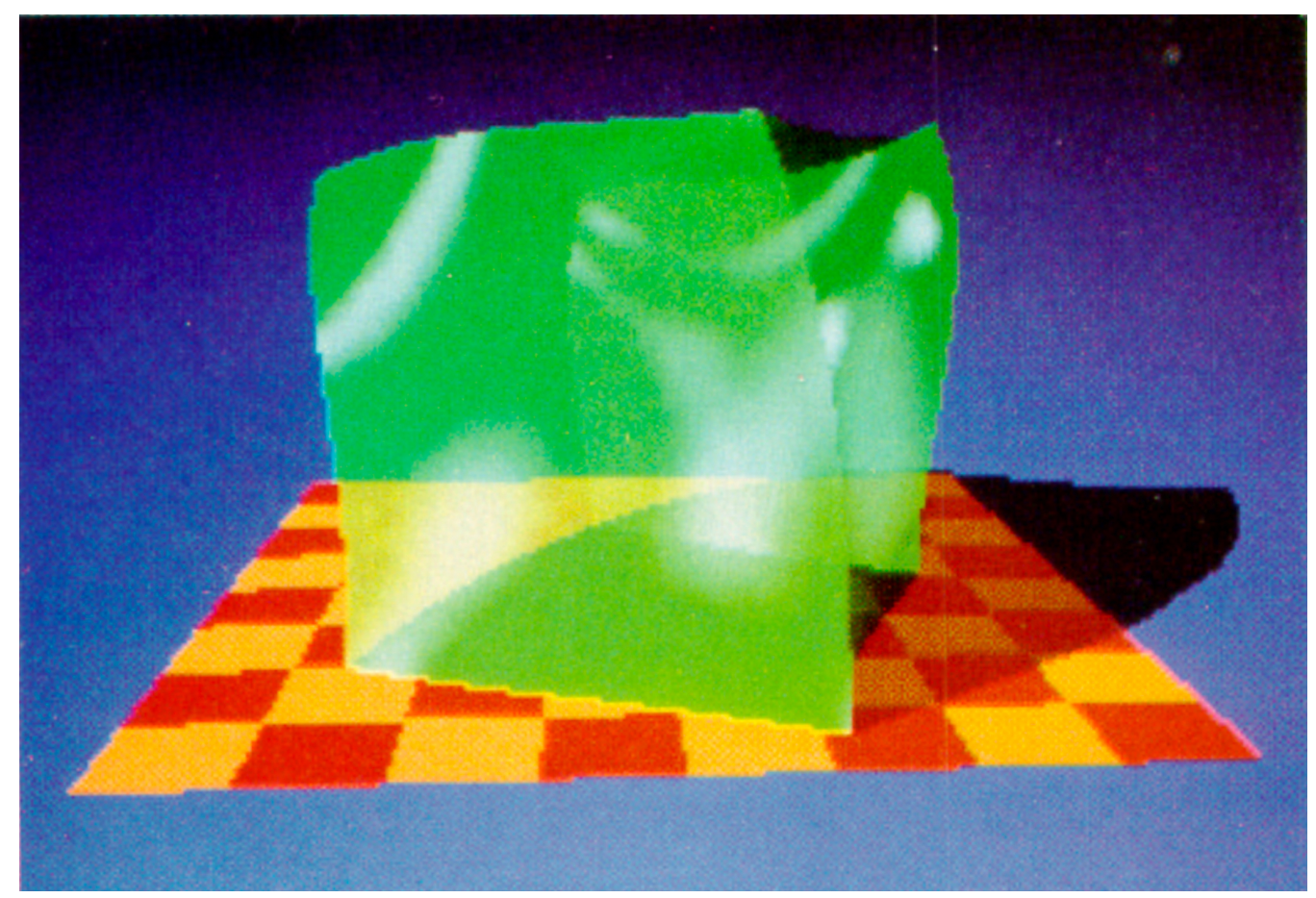

Figure 6: A rendering of lime Jell-O ${ }^{\mathrm{TM}}$ (Heckbert 1987).

Courtesy of Paul Heckbert.

in-joke" (McGuire 2016, 11), offhand references to Jell- $\mathrm{O}^{\mathrm{TM}}$ abound in the computer graphics literature as an ultimate goal in rendering deformable models and as an homage to Paul Heckbert, a ray-tracing pioneer at Pixar who first introduced the concept of rendering Jell- ${ }^{\mathrm{TM}}$ in a mock paper accepted to the SIGGRAPH conference. The paper, entitled "Ray Tracing Jell-O Brand Gelatin," was intended as a parody of computer science research discourse detailing the exploits of Pixar's imaginary "Dessert Food Division" (Heckbert 1987) (figure 6). A lively thread on a computer graphics newsgroup soon after the paper's publication revealed that a few researchers had complained about the paper being a waste of space in SIGGRAPH's proceedings, while others thought that rendering Jell-O ${ }^{T M}$, albeit silly, "can stimulate thought and sometimes leads to novel solutions" (King 1988). Some remarked on the appropriateness of the article given the difficulties of rendering food (Davis 1988). It turns out that the email thread itself was a gag, with Paul Heckbert having started the diatribe against his own paper. As one commentator on the thread replied, "Long after everyone's forgotten all of Paul's serious professional papers, 'Ray Tracing Jell-O Brand Gelatin' will live on. I guess the joke's on him" (Perens 1988).

In the computer graphics literature, Jell- $\mathrm{O}^{\mathrm{TM}}$ becomes a medium to think with, a kind of conceptual and graphic modeling medium that allows researchers and animators to literally stretch the limits of the tools available to them. Similarly, in Cloudy 1, a scene involving a large orange jelly castle prompts the animation team to play around with actual gelatin to understand 


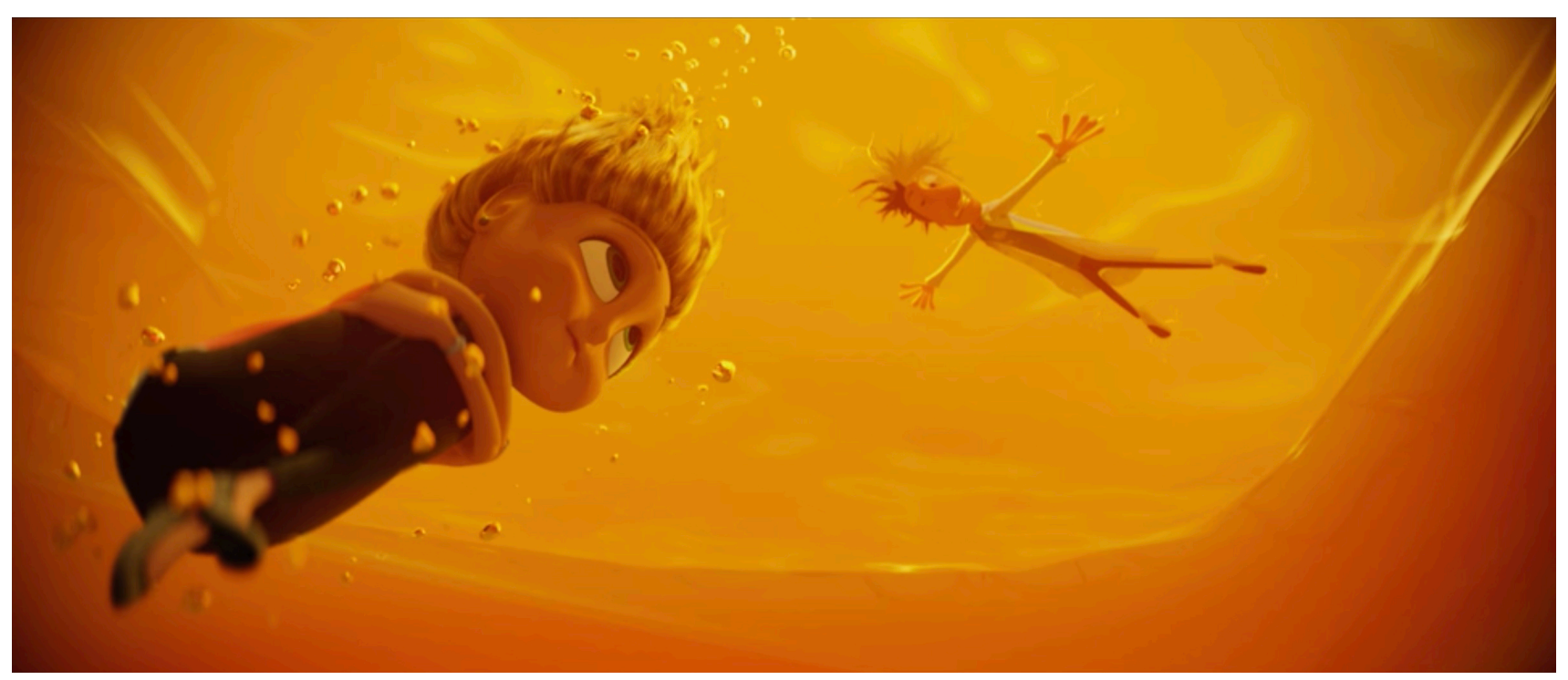

Figure 7: Sam and Flint swimming in the jelly castle (Cloudy 1).

its physical properties: "We brought some Jell-O ${ }^{\mathrm{TM}}$ just to shoot it. And we dropped some things on it to see what that would look like" "“A Recipe" 2010). In light of Heckbert's 1987 article, the castle would seem to be an homage to Heckbert's legacy in the field of ray tracing, but that legacy is never explicitly referred to in the making-of companion film to Cloudy 1, A Recipe for Success. Yet the way in which the Cloudy animation team discusses the gelatin is similar to discussions in the late 1980s about deformable models: "It's always wobbling and jiggling. The light's always changing ... the light has to bounce around like [sic] however many thousand times. It's very difficult to do . . . but they did it" ("A Recipe" 2010). Moreover, the Jell-O TM castle, which Flint constructs in honor of his love interest Sam Sparks, prompts Sam to nervously comment on its amorphous qualities as well as its status as food: "So, Jell-O. It's a solid; it's a liquid; it's a visco-elastic polymer made of polypeptide chains, but you eat it!" (Cloudy 1). Here, Jell-O ${ }^{\text {TM }}$ becomes not only a medium to think with but an actual environment to think in since Flint and Sam enter the structure and move around in it (figure 7). Moving the characters within gelatin posed problems for the animators because the translucent quality of the Jell-O ${ }^{\mathrm{TM}}$ made it difficult to distinguish between people and background: "What happens first? Do you animate the characters? Or do you animate the environment?" (“A Recipe” 2010). While the production team presents its successful rendering of the jelly castle as a technical triumph, their challenges in bringing it to fruition draw attention to the way in which food as a medium stretches the capacities of computer graphics to model the world.

In this way, Jell- $\mathrm{O}^{\mathrm{TM}}$, in terms of both production and plot, unwittingly calls into question the boundaries and hierarchies between character and environment, human and nonhuman. I say unwittingly because as much as the Cloudy films exhibit a tension endemic to many animated films between their "portrayal of plasmatic bodies" and their "reification of nature" (Heise 
2014, 304-5), they are ultimately a product of a capitalist enterprise that has creativity - and the controversial labor practices and intensive energy use that entails-baked into its business model (Leslie and McKim 2017, 210). At his recent SIGGRAPH keynote, Rob Bredow spoke about the importance of "creative problem-solving" in all his commercial projects to date (SIGGRAPH Conferences 2018). This approach is similar to the notion of Pixar Animation Studios as a "fun factory" (Lane 2011) that would likely regard stunts such as Paul Heckbert's SIGGRAPH paper on rendering Jell-O ${ }^{\text {TM }}$ as a harmless expression of its corporate culture, all the while peddling "polished products distorting specific traces of work and world" (Herhuth 2017, 5). The tensions present in the Cloudy franchise echo what Eric Herhuth $(2017,12)$ has called the "exploratory, experimental orientation toward knowledge and politics" in the work of Pixar. That sort of "experimental orientation" is what allows Pixar's stories, according to Herhuth $(2017,12)$, to present "aesthetics as a contested domain, at once inclined toward market-oriented newness and innovation as well as criticism and pluralistic thought." Similarly, the Cloudy films of Sony Pictures Animation act as playful experiments in postAnthropocene world-making while they are also rooted in neoliberal commercial production practices.

This tension between theme and the conditions of production is a symptom of what Herhuth $(2017,2)$ describes as "an affinity ... between animation and the abstract, technological, moving parts of life and culture in late capitalist society." Herhuth $(2017,1)$ sees this affinity manifesting "through two, interactive levels: characters discovering their worlds and audiences watching and thinking about that discovery." In the Cloudy films, Flint Lockwood and his friends discover the phenomenon of food weather and the foodimals alongside the audience and frequently mirror the audience's feelings of astonishment at the animated spectacle before them (figure 8). Cloudy 2 codirector Kris Pearn comments, "When Flint enters the food-centric ecosystem, he's overwhelmed. His creativity is everywhere, encompassing everything around him. It's a message along the lines of 'You can't always control what you make and how it is perceived by the world" (Miller-Zarneke 2013, 143). This statement is true to a limited extent in the actual creation of the films, since the physics-based engines sometimes created unexpected visuals that conferred a kind of autonomy on the animations of food weather. But the potential was still there for animators, through real-time rendering, to potentially tweak and choreograph every last sesame seed on every last bun, thereby appearing to fulfill what Walter Murch describes as the Faustian dream of completely controlling the image through digital cinematography (Murch 1999).

\section{Conclusion}

This paper has explored the ways in which humanists can come to terms with the issue of human extinction through the imaginative and comic work of environmental animation, which Nicole Starosielski describes as a place to explore and question established understandings of the environment. She 


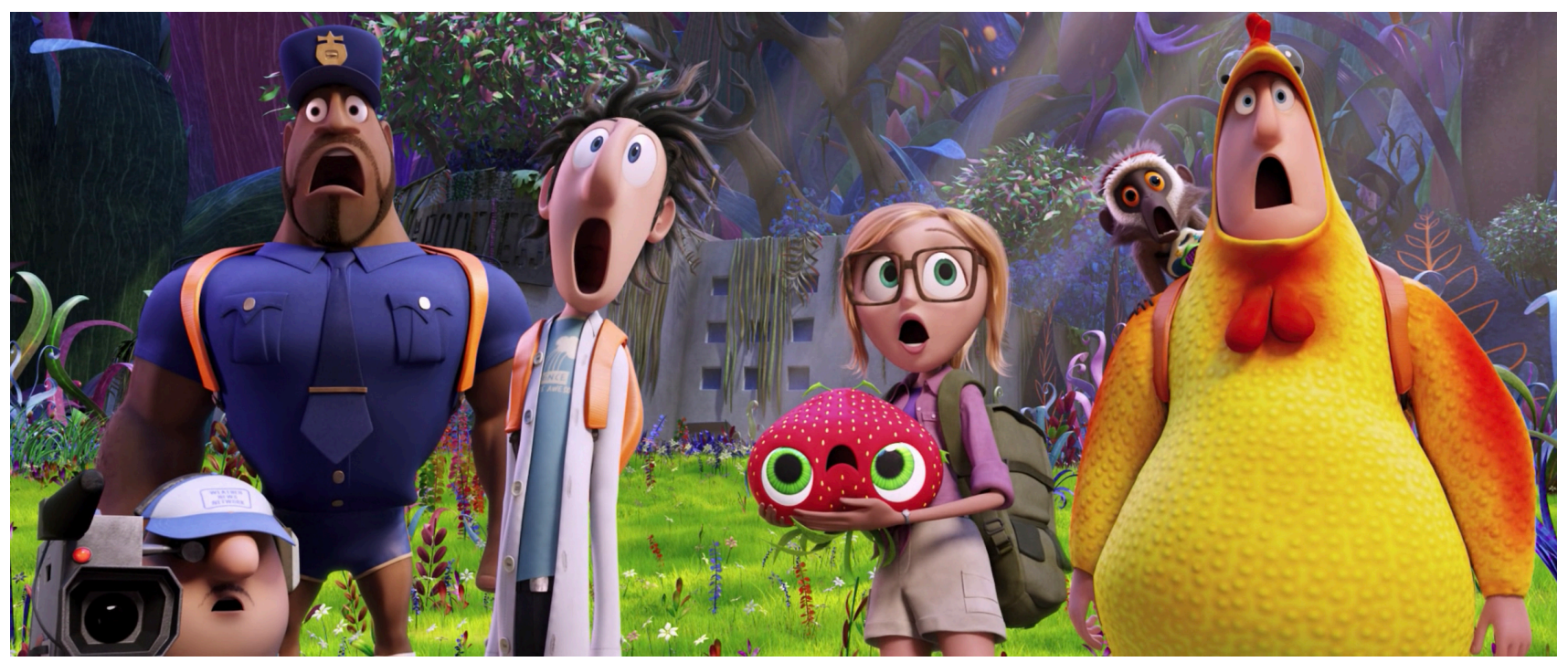

Figure 8: Flint and the gang gasp upon witnessing the foodimals' ecosystem (Cloudy 2).

traces a chronological trajectory from mutability to interactivity to the constructed nature of the environment, a process that parallels the global intensification of extractive capitalism from the postwar period to the present. The Cloudy franchise demonstrates the way in which, in Eric Herhuth's terms, animation's life-giving properties on the level of image are an appropriate medium for late capitalism, which aims to squeeze every last drop of value from every aspect of life (Braidotti 2019, 48). On the level of diegesis, the villains in both Cloudy films see the FLDSMDFR as the key to world domination in the sense that it gives them the power of agrilogistics - to render all nonhuman entities into human fodder - without the attendant backbreaking labor.

On the level of production, advances in near-real time rendering are in the same agrilogistical vein as the machinations of the films' villains. Near-real time rendering makes the creation of complex worlds less resource intensive in terms of computer processing power but squeezes out more work from laborers who now are free to tease out variations in animated movement rather than sit idly by, waiting for the render to finish. As a cost-saving measure, near-real time rendering goes along with other cost-saving measures that SPI undertook in the same time period, including shifting many of its animators from employees to independent contractors and moving their operations from Los Angeles to Vancouver (Cohen, Colebrook, and Miller 2014).

On the level of spectatorship, the net result of all these labor-and cost-saving measures is a lush world that approaches the immersiveness of virtual reality with its breathtaking detail, but without the nausea. By tantalizing viewers with food that's good enough to eat, the Cloudy films engage the spectator's hunger for moving images and sensory engagement, bringing to the fore the inherently "embodied experience" of going to the movies (Sobchack 2004, 76). As the object of animation, however, food resists representation. It wiggles; 
it jiggles; its infinitely varied surfaces reflect light in unpredictable ways. The conceit and techniques of rendering food weather in the Cloudy films therefore provide food for thought for ways of mediating the environment through both art and science.

C. P. Snow's vague sense of the spiritual loss that likely occurred in the transition from hunter-gatherer societies to settled agricultural ones seems prescient given the current sense of paralyzing loss that is being felt by humans in a world on the brink of extinction. But what was lost, along Snowian lines, was more likely the humility that comes with knowing that one could always be someone else's dinner and that ultimately all living things turn into food for worms. 


\section{REFERENCES}

"A Recipe for Success: The Making of Cloudy with a Chance of Meatballs." 2010. Produced by Blink Digital. ITunes Extras. Streaming Video. https://itunes.apple.com/us/movie/cloudy-with-achance-of-meatballs/id345236501? $\mathrm{mt}=6$ \&ign-mpt=uo\%3D4.

Alaimo, Stacy. 2016. Exposed: Environmental Politics and Pleasures in Posthuman Times. Minneapolis: University of Minnesota Press. https://doi.org/10.5749/minnesota/ 9780816621958.001.0001.

Barnett, Joshua Trey. 2018. "Politics of Edibility: Reconceptualizing Ecological Relationality." Environmental Communication 12 (2): 218-31. https://doi.org/10.1080/ 17524032.2015.1127853.

Barrett, Judi. 1978. Cloudy with a Chance of Meatballs. New York: Simon \& Schuster.

Barthes, Roland. 2013. “Toward a Psychosociology of Contemporary Food Consumption.” In Food and Culture: A Reader, edited by Carole Counihan and Penny Van Esterik, 23-30. New York: Taylor \& Francis.

Boulos, Daniel N. 2016. "Abstraction and Stylized Design in 3D Animated Films: Extrapolation of 2D Animation Design." In Encyclopedia of Computer Graphics and Games, edited by N. Lee, 1-11. Springer International Publishing. https://doi.org/10.1007/978-3-319-08234-9 58-1.

Boykoff, Maxwell T., Marisa B. McNatt, and Michael K. Goodman. 2015. "Communicating in the Anthropocene: The Cultural Politics of Climate Change News Coverage Around the World.” In The Routledge Handbook of Environment and Communication, edited by Anders Hansen and Robert Cox, 221-31. New York: Routledge.

Braidotti, Rosi. 2019. "A Theoretical Framework for the Critical Posthumanities.” Theory, Culture ES Society 36 (6): 31-61. https://doi.org/10.1177/0263276418771486.

Brereton, Pat. 2014. “Animated Ecocinema and Affect.” In Moving Environments: Affect, Emotion, Ecology, and Film, edited by Alexa Weik Von Mossner, 181-200. Waterloo: Wilfrid Laurier University Press.

-_- 2015. "Cinema, Ecology, and Environment." In The Routledge Handbook of Environment and Communication, edited by Anders Hansen and Robert Cox, 258-69. New York: Routledge.

Carruth, Allison. 2018. "Wily Ecologies: Comic Futures for American Environmentalism.” American Literary History 30 (1): 108-33. https://doi.org/10.1093/alh/ajx044.

Carruth, Allison, and Robert P. Marzec. 2014. "Environmental Visualization in the Anthropocene: Technologies, Aesthetics, Ethics.” Public Culture 26 (2): 205-11. https://doi.org/10.1215/ 08992363-2392030.

Chow, Rey. 2011. "When Reflexivity Becomes Porn: Mutations of a Modernist Theoretical Practice.” In Theory After 'Theory,' edited by Jane Elliott and Derek Attridge, 135-49. New York: Routledge.

Cloudy with a Chance of Meatballs. 2009. Directed by Phil Lord and Chris Miller. iTunes. Streaming video. https://itunes.apple.com/us/movie/cloudy-with-a-chance-of-meatballs/ $\underline{\mathrm{id} 345236501 \text { ? } \mathrm{mt}=62 \mathrm{ign}-\mathrm{mpt}=\mathrm{uo} \% 3 \mathrm{D} 4}$.

Cloudy with a Chance of Meatballs 2. 2013. Streaming video. Directed by Cody Cameron and Kris Pearn. iTunes. https://itunes.apple.com/us/movie/cloudy-with-a-chance-of-meatballs-2/ id699011844. 
Cohen, Tom, Claire Colebrook, and J.Hillis Miller. 2014. Twilight of the Anthropocene Idols. Ann Arbor, MI: Open Humanities Press. http://www.openhumanitiespress.org/books/titles/twilightof-the-anthropocene-idols/.

Colebrook, Claire. 2014. Death of the PostHuman: Essays on Extinction, Volume One. Ann Arbor, MI: Open Humanities Press. https://doi.org/10.3998/ohp.12329362.0001.001.

Crutzen, Paul J., and Eugene F. Stoermer. 2000. "The Anthropocene.” Global Change Newsletter 41 (May): 17-18. http://www.igbp.net/download/18.316f18321323470177580001401/ 1376383088452/NL41.pdf.

Cubitt, Sean. 2012. “Everybody Knows This Is Nowhere.” In Ecocinema Theory and Practice, edited by Salma Monani and Sean Cubitt, 279-96. New York: Routledge.

Davis, Brad. 1988. "Message 5304. "Ray Tracing Jell-O Brand Gelatin.” Comp.Graphics Newsgroup, March 3, 1988. https://web.mit.edu/kolya/.f/root/athena.mit.edu/net/user/chris/jell-o.saga.

Feeding America. 2009a. “Advancing Hope for a Hunger-Free America: 2009 Annual Report.”

_-_. 2009b. "Become a Hunger Helper.” SHofStJoe Channel, You Tube.” https://www.youtube.com/watch?v=ZLW7H9DWcK4.

- - . 2013. "Sony Pictures Animation's 'Cloudy with a Chance of Meatballs 2' Feeds America with the Help of Some of the Nation's Leading Produce Companies to Support Hunger Action Month with over 200,000 Pounds of Donated Produce." Feedingamerica.Org, September 9, 2013. https://www.feedingamerica.org/about-us/press-room/sony-pictures-animations-cloudy-with-achance-of-meatballs-2-feeds-america-with-the-help-of-some-of-the-nations-leading-producecompanies-to-support-hunger-action-month-with-over-200000-pounds-of-donated-produce.

Garrard, Greg. 2011. Ecocriticism. New York: Routledge. https://doi.org/10.4324/ 9780203806838.

Govil, Dhruv. 2017. "Animation Collaboration with Depth Compositing." In ACM SIGGRAPH 2017 Talks on - SIGGRAPH '17. ACM Press. https://doi.org/10.1145/3084363.3085039.

Heckbert, Paul S. 1987. "Ray Tracing Jell-O Brand Gelatin.” ACM SIGGRAPH Computer Graphics 21 (4): 73-74. https://doi.org/10.1145/42372.42375.

Heise, Ursula K. 2014. "Plasmatic Nature: Environmentalism and Animated Film.” Public Culture 26 (2): 301-18. https://doi.org/10.1215/08992363-2392075.

Herhuth, Eric. 2017. Pixar and the Aesthetic Imagination. Berkeley: University of California Press.

King, Stephen. 1988. "Message 2690: Ray Tracing Jell-O Brand Gelatin.” Comp.Graphics Newsgroup, March 9, 1988. https://web.mit.edu/kolya/.f/root/athena.mit.edu/net/user/chris/jello.saga.

Kulla, Christopher, Alejandro Conty, Clifford Stein, and Larry Gritz. 2018. "Sony Pictures Imageworks Arnold." ACM Transactions on Graphics 37 (3): 1-18. https://doi.org/10.1145/ $\underline{3180495}$.

Landecker, Hannah. 2011. "Food as Exposure: Nutritional Epigenetics and the New Metabolism.” Biosocieties 6 (2): 167-94. https://doi.org/10.1057/biosoc.2011.1.

Lane, Anthony. 2011. “The Fun Factory: Life at Pixar.” New Yorker, May 9, 2011. https://www.newyorker.com/magazine/2011/05/16/the-fun-factory. 
Lee, Patrick. 2006. “Meatballs Spoofs Disaster Flicks.” SciFi Wire, August 21, 2006. https://web.archive.org/web/20060821120206/http://www.scifi.com/scifiwire/ index.php?category $=0 \& \mathrm{id}=37514$.

Leslie, Esther, and Joel McKim. 2017. "Life Remade: Critical Animation in the Digital Age.” Animation 12 (3): 207-13. https://doi.org/10.1177/1746847717740841.

Leyda, Julia, and Diane Negra, eds. 2015. Extreme Weather and Global Media. New York: Routledge. https://doi.org/10.4324/9781315756486.

Martinez, Adam, and Terrance Tornberg. 2010. "Lighting and RenderingAlice in Wonderland." In ACM SIGGRAPH 2010 Talks on - SIGGRAPH'10. ACM Press. https://doi.org/10.1145/ $\underline{1837026.1837028 .}$.

McGuire, Morgan. 2016. "Peering through a Glass, Darkly at the Future of Real-Time Transparency." SIGGRAPH 2016 Open Problems in Real Time Rendering Course, July 26, 2016. https://casual-effects.com/research/McGuire2016Darkly/McGuire2016Darkly-small.pdf.

Miller-Zarneke, Tracey. 2013. The Art of Cloudy with a Chance of Meatballs 2. Petaluma, CA: Cameron Books.

Mirzoeff, Nicholas. 2014. "Visualizing the Anthropocene." Public Culture 26 (2): 213-32. https://doi.org/10.1215/08992363-2392039.

Mitchell, Robert. 2010. Bioart and the Vitality of Media. Seattle: University of Washington Press.

Morton, Timothy. 2012. “The Oedipal Logic of Ecological Awareness.” Environmental Humanities 1 (1): 7-21. https://doi.org/10.1215/22011919-3609949.

- - . 2013. Hyperobjects: Philosophy and Ecology after the End of the World. Minneapolis: University of Minnesota Press.

- - . 2016. Dark Ecology: For a Logic of Future Coexistence. New York: Columbia University Press. https://doi.org/10.7312/mort17752.

Murch, Walter. 1999. “A Digital Cinema of the Mind? Could Be.” New York Times, May 2, 1999. https://archive.nytimes.com/www.nytimes.com/library/film/050299future-film.html.

Nudd, Tim. 2009. "Weather Channel Gives 'Meatballs’ Forecasts.” Adweek Blogs, 2009. https://www.adweek.com/creativity/weather-channel-gives-meatballs-forecasts-13652/.

Opie, John, and Norbert Elliot. 1996. "Tracking the Elusive Jeremiad: The Rhetorical Character of American Environmental Discourse." In The Symbolic Earth: Discourse and Our Creation of the Environment, edited by James Gerard Cantrill and Christine L. Oravec, 9-37. Lexington: University of Kentucky Press.

Perens, Bruce. 1988. "Message 1562: Ray Tracing Jell-O Brand Gelatin.” Comp.Graphics Newsgroup, March 3, 1988. https://web.mit.edu/kolya/.f/root/athena.mit.edu/net/user/chris/jello.saga.

"Physically-Based Modeling: Past, Present, and Future." 1989. In Panel Proceedings, ACM SIGGRAPH. http://web.cs.ucla.edu/ dt/siggraph89-panel/.

Post Magazine. 2013. "Film Sound: Cloudy with a Chance of Meatballs 2," November 1, 2013. https://www.postmagazine.com/Publications/Post-Magazine/2013/October-1-2013/Film-SoundCloudy-with-a-Chance-of-Meatballs-2.aspx.

Robertson, Barbara. 2009. "Food for Laughs.” CGW 32 (9): 14-20. http://www.cgw.com/ Publications/CGW/2009/Volume-32-Issue-9-Sep-2009-/Food-for-Laughs.aspx. 
Seymour, Mike. 2012. “The Art of Rendering.” Fxguide, April 10, 2012.

https://www.fxguide.com/featured/the-art-of-rendering/.

Seymour, Nicole. 2018. Bad Environmentalism: Irony and Irreverence in the Ecological Age. Minneapolis: University of Minnesota Press. https://doi.org/10.5749/j.ctv65sz3q.

SIGGRAPH Conferences. 2018. "Rob Bredow: 'Everything We Do Is Creative.” ACMSIGGRAPH Blog, June 19, 2018. https://blog.siggraph.org/2018/06/qa-withsiggraph-2018-keynote-rob-bredow.html.

Smailbegović, Ada. 2015. "Cloud Writing: Describing Soft Architectures of Change in the Anthropocene." In Art in the Anthropocene, edited by Heather Davis and Etienne Turpin, 93-108. Ann Arbor, MI: Open Humanities Press.

Snow, C.P. 1993. The Two Cultures. New York: Cambridge University Press.

Sobchack, Vivian. 2004. Carnal Thoughts: Embodiment and Moving Image Culture. Berkeley: University of California Press.

Starosielski, Nicole. 2011. “'Movements That Are Drawn': A History of Environmental Animation from The Lorax to FernGully to Avatar." International Communication Gazette 73 (1-2): 145-63. https://doi.org/10.1177/1748048510386746.

Stephens, John. 2010. "Impartiality and Attachment: Ethics and Ecopoeisis in Children's Narrative Texts." International Research in Children's Literature 3 (2): 205-16. https://doi.org/10.3366/ ircl.2010.0108.

Szerszynski, Bronislaw. 2010. "Reading and Writing the Weather: Climate Technics and the Moment of Responsibility." Theory, Culture E' Society 27 (2-3): 9-30. https://doi.org/10.1177/ $\underline{0263276409361915 .}$

Taylor, Ella. 2009. “"Meatballs' Comes with a Helping of Social Critique.” NPR.Org, September 17, 2009. https://www.npr.org/templates/story/story.php?storyId=112635896.

Todd, Anne Marie. 2015. “Cartoons and the Environment.” In The Routledge Handbook of Environment and Communication, edited by Anders Hansen and Robert Cox, 250-57. New York: Routledge.

Whitley, David. 2012. The Idea of Nature in Disney Animation. Burlington, VT: Ashgate.

Wolf, Mark J.P. 1999. “Subjunctive Documentary: Computer Imaging and Simulation.” In Collecting Visible Evidence, edited by Jane Gaines and Michael Renov, 274-91. Minneapolis: University of Minnesota Press. 